\title{
Recent patterns in cutaneous melanoma descriptive epidemiology in the Slovak Republic
}

\author{
M. ONDRUSOVA ${ }^{1,2,3 *}$, B. MRINAKOVA ${ }^{4}$, D. ONDRUS ${ }^{5}$, K. POLAKOVA $^{6}$, S. DURDIK $^{7}$
}

${ }^{1}$ Cancer Research Institute, Slovak Academy of Sciences, Bratislava, Slovak Republic; ${ }^{2}$ St. Elisabeth University of Health and Social Work, Bratislava, Slovak Republic; ${ }^{3}$ Pharm-In, Bratislava, Slovak Republic; ${ }^{4}$ Department of Clinical Oncology, St. Elisabeth Cancer Institute, Bratislava, Slovak Republic; ${ }^{5}$ 1st Department of Oncology, Comenius University, Faculty of Medicine, St. Elisabeth Cancer Institute, Bratislava, Slovak Republic; ${ }^{6}$ Dermatologic Outpatient Unit, St. Elisabeth Cancer Institute, Bratislava, Slovak Republic; ${ }^{7}$ Department of Oncological Surgery, Comenius University, Faculty of Medicine, St. Elisabeth Cancer Institute, Bratislava, Slovak Republic

${ }^{*}$ Correspondence: martina.ondrusova@hotmail.com

Received September 16, 2012 / Accepted March 18, 2013

An increase in melanoma incidence in the Slovak Republic (SR) is evident during approximately the same time and maybe caused by changes in socio-economic status. The paper analyses national trends in incidence, mortality, survival and clinical stages of invasive cutaneous melanoma in the SR from 1968-2007. The trends in incidence and mortality have been extracted between 1968-2007 period by the joinpoint regression analysis, clinical stages were analysed in 1978-2003. Survival data were extracted from the national database resources. Socio-economic changes, which reflected in increase in the number of holidaymakers to seaside and mountainous destinations happened in the country in the y.1989. Subsequently, according to joinpoint in 1997, acceleration of increment of the incidence values of melanoma was recorded in both sexes. Mortality was increasing in males continuously, in females the stabilization was registered after the year 1999. Lower rates of relative survival might be influenced by delayed accessibility to adjuvant treatment. The number of cases diagnosed in clinical stage I increased significantly. The changes in the intensity and excessive sunbathing during vacations might be one of many factors that participate in subsequent acceleration of the increment of incidence not only in the SR.

Key words: cutaneous melanoma - epidemiology, incidence, mortality, clinical stages, survival

The risk of developing malignant cutaneous melanoma varies remarkably according to skin pigmentation and ultraviolet irradiation from the sun. In Europe, melanoma represents a major public health challenge [1] and according to recent worldwide estimates in 2008 [2], it is the $10^{\text {th }}$ most common cancer in males and the $7^{\text {th }}$ in females. A sharp increase in melanoma incidence has been attributed to excessive exposure to sunlight [3].

According to the estimates of IARC WHO for 2008 [2], melanoma incidence in Europe in males was 7.6/100 000, in females 7.8/100 000. Mortality in males was 1.9/100 000 and in females 1.3/100 000, the average European rates of incidence and mortality are higher than the worldwide average [2].

In several countries of Central and Eastern Europe, similar changes in melanoma incidence and mortality trends have been registered approximately since the second half of the1990s [2, 4]. The Slovak Republic (SR), a country located in the centre of Europe with a mild climate, has higher melanoma incidence rates than the European average. According to the impact of the main risk factor (extensive solar radiation), the possible exposure of the population significantly changed after noticeable socio-economic changes, which occurred in the y. 1989 after the fall of communism. The purpose of this study is to analyse melanoma incidence's trends and clinical stages with resulting mortality as well as possible reasons for any differences discovered in the SR. The migration of the population in the SR (as a risk factor which is probably related to solar radiant exposure at the place of residence early in life [5]) and changes in the climate during the course of the analysed period have not been taken into account due to their insignificance for the situation in the SR [6].

This study brings a new perspective on the long-term evolution (1968-2007) of incidence and mortality of cutane- 
ous melanoma in the SR, representation of its clinical stages, and also relative survival rates in the SR. The paper discusses possible factors affecting these trends and compares national data to an appropriate broader international context. We noted a subsequent statistically significant increase of the values of incidence after the liberation from the totalitarian regime and an improvement in the indicators of mortality especially in females, influenced by better and more effective diagnosis and treatment.

\section{Material and methods}

The data concerning the incidence of invasive cutaneous melanoma used in this analysis were obtained from the preprocessed data portal of the National Cancer Registry (NCR) SR [4] (www.nor-sk.org) valid until the end of July 2009 as well as from the standard outcomes and annual reports of the NCR SR [7-11]. NCR SR is a population-based, cancer registry, which covers the entire SR (approximately 5.5 million people) and relies on mandatory cancer notifications from health care sources and death certificates from the Statistical Office of the SR. Information on mid-year population and mortality data were obtained from the Statistical Office of the SR as the "Official Mortality Data", with no ability to cite the resources. Incidence and mortality data from other countries that are compared with the situation in the SR, were obtained from the GLOBOCAN 2008 cancer database of the IARC WHO [2]. Analyses of the overall incidence and mortality in the SR consider the period 1968-2007 for which validated data for the SR exists. The values of incidence and mortality are presented in the form of crude rates in 2007 [11]. The comparison with other countries is possible only after a correction of the different age structure of the population. A standardization to the World standard population was performed [12] and the age standardized rates-world (ASR-W) in the SR and other countries have been compared. The trends in incidence and mortality have been extracted separately for each gender between 1968-2007 and were carried out by the joinpoint regression analysis using the software Joinpoint Regression Program, Version 3.5.3 [13]. The analysis included maximum number of four joinpoints, and minimum of four years between two joinpoints. All other program's parameters were set to default values. The aim of the approach is to identify possible joinpoints where a significant change in the trends occurs. The method identifies joinpoints based on regression models with $0-4$ joinpoints. The final selected model was the most parsimonious of these [14]. To quantify the trend over a fixed period, the annual absolute change from the modelled data was calculated. The trends are presented with a corresponding $95 \%$ Confidence Intervals (CI) and p-value with the null hypothesis being constant with time. The analyses of the clinical stages are based upon the period 1978-2003, which is the period for which the SR had, within the framework of the web portal www.nor-sk.org [4], data about the stages of the disease that were open to the community of specialists. At the same time, it took into account changes in the coding system that occurred only once in the period analysed (in 2000 with the transition from TNM- $3^{\text {rd }}$ ed. to TNM- $4^{\text {th }}$ ed.). Survival data were extracted from the national database resources [10], where the Kaplan-Meier method was used to estimate survival functions. Age-specific characteristics of incidence were obtained from the publications of National Cancer Registry, which are available only in the time-period of 1980-2005 [4, 7-9]. Other melanoma characteristics (e.g. Breslow thickness, the body-site distribution etc.) could not be compiled into the analysis due to the inaccessibility of this data from the NCR SR to the expert community.

\section{Results}

In 2007 in the SR, 333 cases of cutaneous melanoma in men were diagnosed. This represented crude incidence 12.7/100 000 and standardized (ASR-W) 9.6/100 000 (95\% CI \pm 1.050 ). In 2007, melanoma comprised $2.4 \%$ of the total cancer occurrence in the male population and was on the $9^{\text {th }}$ place. The index of the increment of the ASR-W incidence for year 1968 is 5.1, from ASR-W incidence 1.9/100 $000(95 \% \mathrm{CI} \pm 0.574)$ in 1968 to the current $9.6 / 100000$. Incidence rates in men increased over the entire period, with the best fitting model having a joinpoint in 1997 (CI $95 \%$ 1995-2000), resulting in two separate trends: in the y. 1968-1997 there was recorded a gentle increase of incidence for the value $0.110 / 100000$ annually (CI $95 \% 0.094-0.126, \mathrm{p}<0.0001$ ) and in the y. 19972007 we registered a significant acceleration of incidence for the value of $0.415 / 100000$ annually (CI $95 \% 0.335-0.494$, $\mathrm{p}<0.0001$ ), whereby the alteration of increase incidence in the y. 1997 for the value of $0.305 / 100000$ is also statistically significant (CI $95 \% 0.224-0.386, \mathrm{p}<0.0001)$. The annual percentage change of modelled data on incidence was $3.7 \%$ in 1968-1997 and 5.6 \% in 1997-2007 (Fig. 1).

The age-specific incidence of malignant melanoma in men in the analysed period (1980-2005) has a slight increasing tendency from age group 20-24 y. and a sharp increase tendency from age group 40-44 y. In the analysed periods 1980-1984 to 1995-1999 incidence culminated in 75-79 year old men with subsequent decrease in the age groups $80+\mathrm{y}$. In recent periods 2000-2005 the age-specific incidence has an increasing tendency up to the age-group of 80-84 y., the decrease was registered only at the eldest age groups $(85+\mathrm{y}$. (Fig. 2).

There were 326 newly diagnosed cases of melanoma in women, which represents crude incidence 11.7/100 000, ASR$\mathrm{W}$ incidence $8 / 100000$ (95\% CI \pm 0.912$)$. In 2007, melanoma comprised $2.3 \%$ of all cancers and was the $12^{\text {th }}$ place on the scale of malignancies in women. The incidence continues to have an increasing tendency since 1968, when the index of increment of the ASR-W incidence was 2.67, from an ASR-W incidence 3.0/100 000 (95\% CI \pm 0.679 ) in 1968 to $8 / 100000$ in 2006. Incidence rates in females increased over the entire 


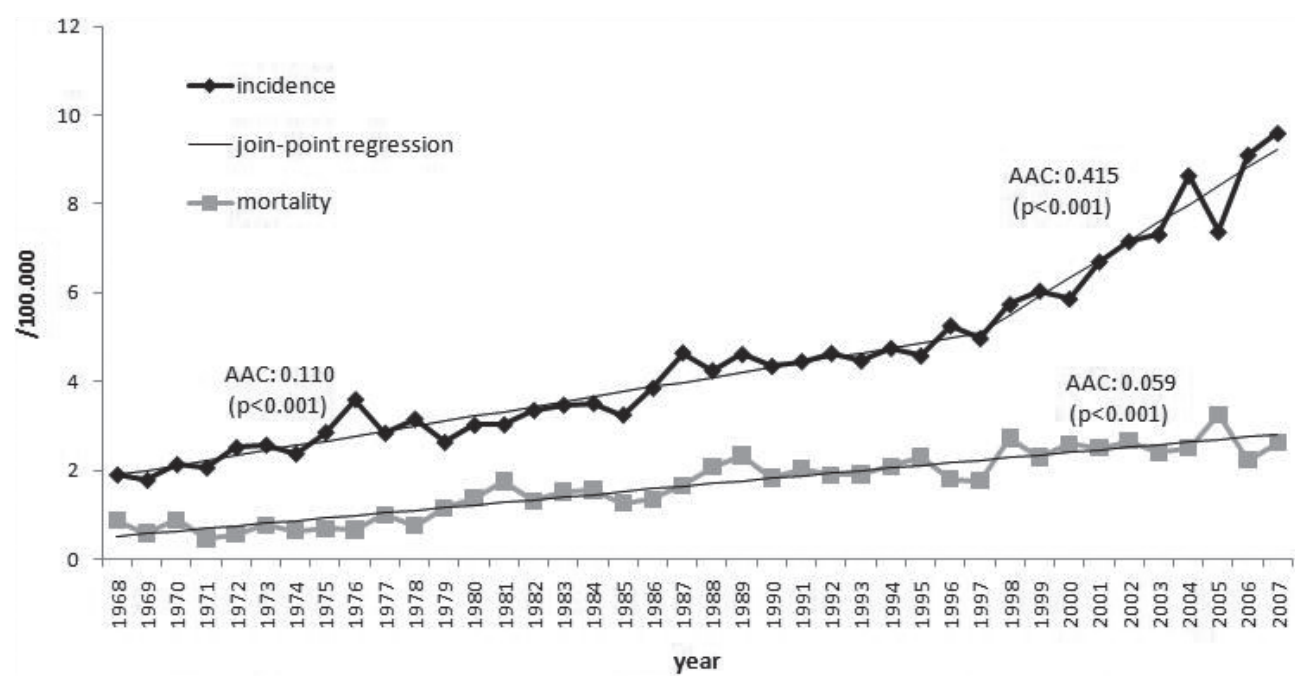

Figure 1. Trends of the age-standardized (to the World standard population - ASR-W) incidence and mortality of cutaneous melanoma and the joinpoint regression in men in the SR, 1968-2007. (AAC=annual absolute change)

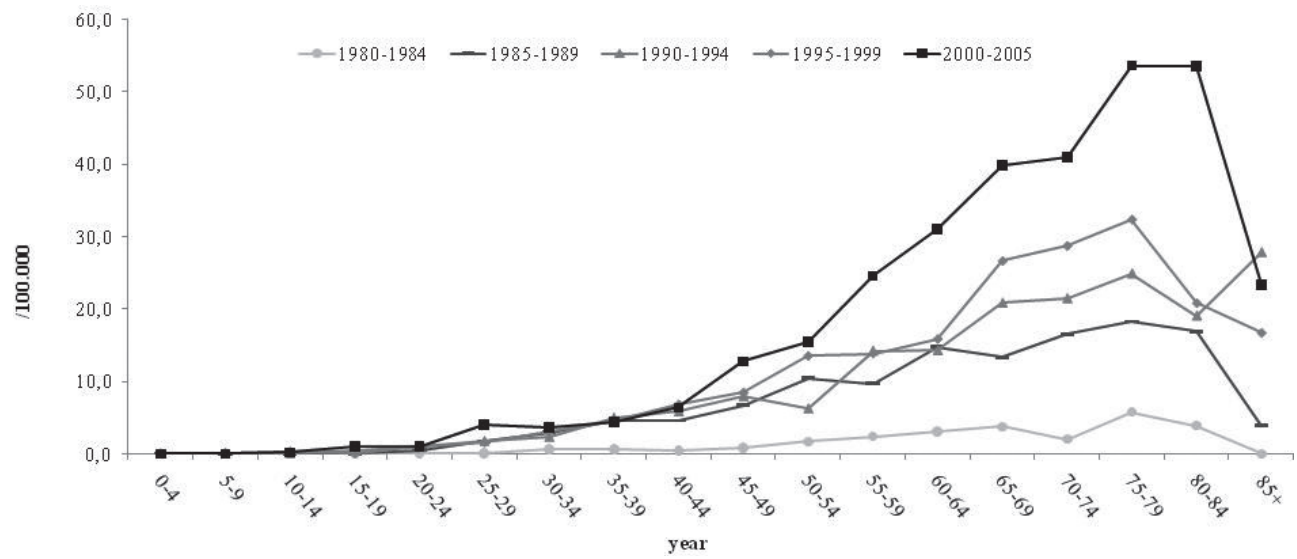

Figure 2. Age-specific incidence trends in males with cutaneous melanoma in the Slovak Republic (time periods 1980-1984 to 2000-2005).

period, with the best fitting model having a joinpoint in 1997 (CI 95 \% 1987-2001), similarly to the situation in incidence evolution in men, whereby the alteration of incidence increment before and after y. 1997 are a little less pronounced than in men: in the y. 1968-1997 it was recorded an increment of the incidence for the value $0.122 / 100000$ annually (CI $95 \%$ $0.100-0.144 ; \mathrm{p}<0.0001)$ in women and in the y. 1997-2007 had the increment of incidence accelerated for the value of 0.266/100 000/annually (CI 95\% $0.158-0.374$, p<0.0001). In the y. 1997 the fluctuation of increment of the incidence represented value $0.145 / 100000$ (CI $95 \% 0.034-0.255$, $\mathrm{p}=0.01$ ). The annual percentage change of modelled data on incidence was $3.5 \%$ in 1968-1997 and 3.7 \% in 1997-2007 (Fig. 3).

The age-specific incidence of malignant melanoma in female in the analysed period (1980-2005) has a sharp increase tendency from the young age group of 20-24 y. In y. 1980-1989 the age-specific incidence had an increasing tendency through the eldest age groups $(85+y$.) However, in periods 1990-1994 to 2000-2005 the age-specific incidence peaked at the age-groups of 80-84 y. and at the eldest age groups of $85+y$. there was registered a sharp decrease in incidence (Fig. 4).

In 2007 in the SR 91 males died of cutaneous melanoma, which represents crude mortality 3.5/100 000 and ASR-W mortality 2.6/100 000 (95\% CI \pm 0.550$)$. The index of the increment of ASR-W mortality was 3.0, from 0.9/100 000 (95\% CI \pm 0.404 ) in 1968 to the current 2.6/100 000. The significantly slight increase in the mortality trend for the value $0.059 / 100.000$ annually (CI $95 \% 0.052-0.067$; $\mathrm{p}<0.0001$ ) was observed over the whole 40 -year period and no additional joinpoints were identified. The annual percentage change of 


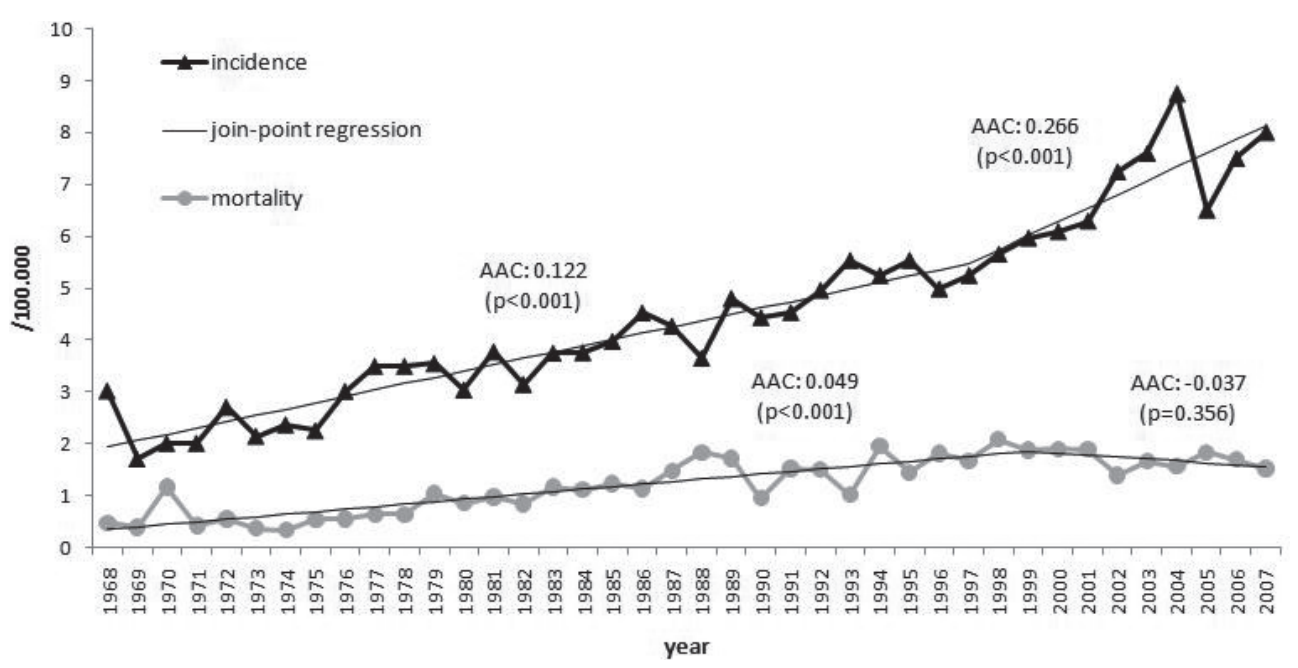

Figure 3. Trends of the age-standardized (to the World standard population - ASR-W) incidence and mortality of cutaneous melanoma and the joinpoint regression in women in the $\mathrm{SR}, 1968-2007$. (AAC=annual absolute change)

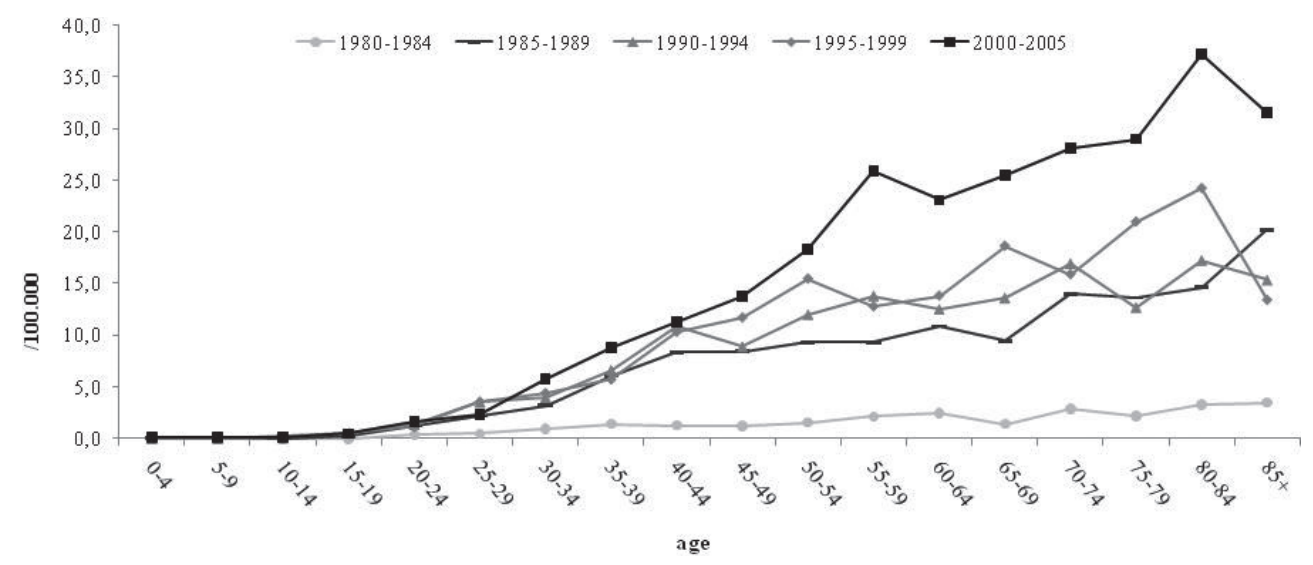

Figure 4. Age-specific incidence trends in females with cutaneous melanoma in the Slovak Republic (time periods 1980-1984 to 2000-2005).

modelled data on mortality was $4.15 \%$ in 1968-2007 (Fig. 1). The overall 5-year survival rate in the SR for male patients from the cohort of the years 2000-2004 (according to the recent national statistic), reached $63.2 \%$; for the cohort of the years 1980-1984 it was $47.4 \%$ [10]. In 2007 in the SR 75 females died of melanoma, which represents crude mortality 2.7/100 000 and ASR-W mortality 1.5/100 000 (95\% CI \pm 0.365$)$. The index of the mortality increment for the year 1968 was 3.0 $\%$; from $0.5 / 100000$ in 1968 (95\% CI \pm 0.277 ) to $1.5 / 100000$ in 2007. Joinpoint analysis in female melanoma mortality identified one joinpoint, in 1999, resulting in two separate trends: from 1968 to 1999 (CI $95 \%$ 1993-2003) the trend showed increasing trend $(0.049 / 100.000 /$ year; CI $95 \% 0.038$ $-0.059, \mathrm{p}<0.0001)$ and from 1999 to 2007 the trend remained stable $(-0.037 / 100.000 /$ year; CI $95 \%-0.117-0.043 ; \mathrm{p}=0.356)$. The annual percentage change of modelled data on female mortality was $5.35 \%$ in $1968-1999$ and $-1.93 \%$ in $1999-2007$ (Fig. 3). The overall 5-year survival of females with malignant melanoma in 2000-2004 was $79.3 \%$ in the SR; for the cohort of the years 1980-1984 it was $62.3 \%$ [10].

In the SR a significant change in the percentage of the melanoma clinical stages was recorded during the period 1978-2003. The number of cases diagnosed in clinical stage I increased significantly for the period 1978-1989 but after 2000 it decreased sharply in both males (Fig. 5) and females (Fig. 6). However, during this period, the TNM coding system was changed. Another significant change in both sexes was a decrease that occurred in the number of cases in the unspecified clinical stage. The number of cases in clinical stages II and IV was relatively stable and at a low level in both genders until 1989 (later changes are influenced by changes in TNM-coding system). 


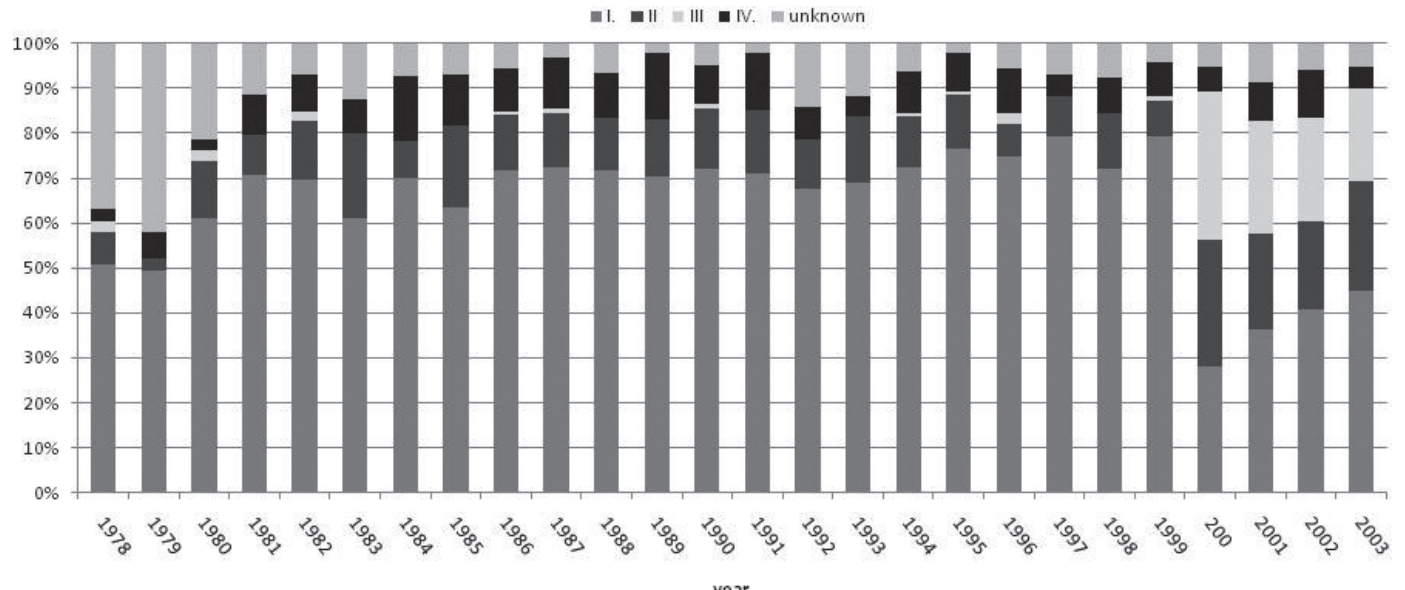

Figure 5. Clinical stages of cutaneous melanoma in men in the Slovak Republic, 1978-2003.

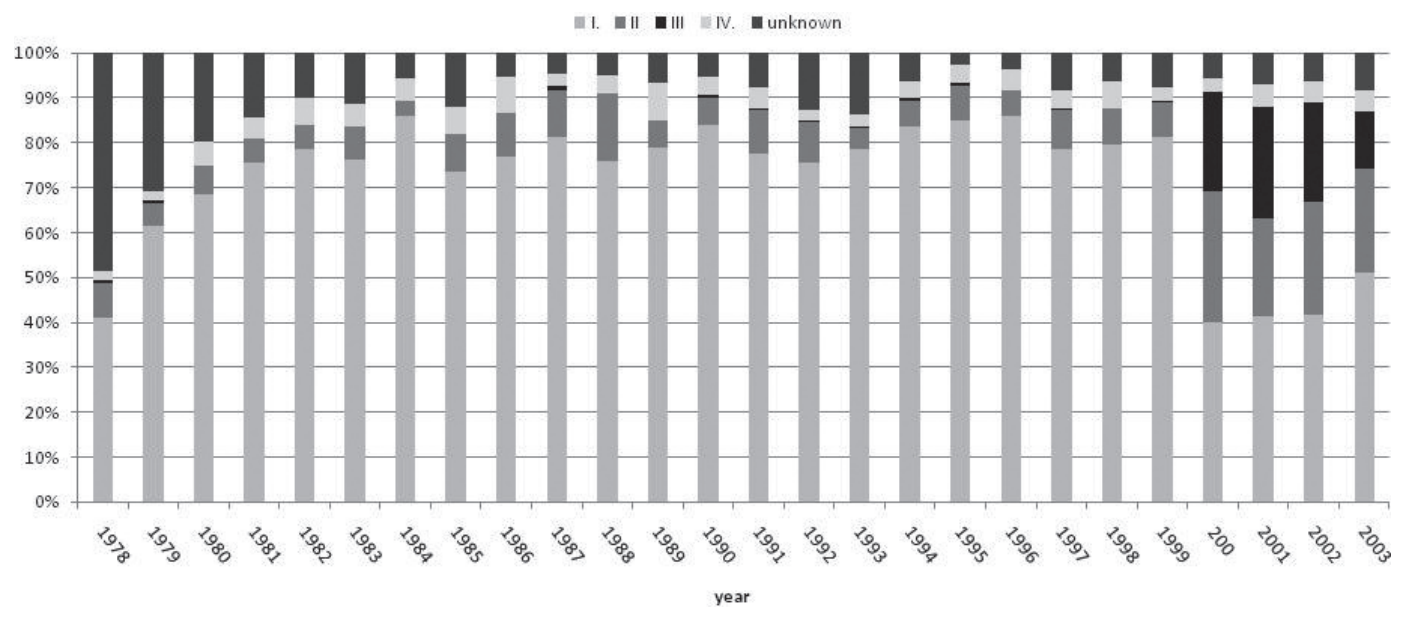

Figure 6. Clinical stages of cutaneous melanoma in females in the Slovak Republic, 1978-2003.

\section{Discussion}

Melanoma of the skin occurs predominantly in white-skinned population living in the countries where there is a high-intensity of ultraviolet radiation. However, this malignancy afflicts all ethnic groups to some degree [15]. The geographical variation in ASR-W incidence rates worldwide is considerable. The highest estimated values of ASR-W incidence in males and females for the year 2008 are in Australia, New Zealand and Oceania. High incidence was also found in some countries of Northern Europe (e.g. in Switzerland, Denmark, and Norway) and in North America. The SR, with its medium rate of ASR-W incidence, placed $20^{\text {th }}$ and $22^{\text {nd }}$ worldwide in males and females, respectively. The lowest rates of ASR-W incidence in 2008 in both genders were found to be in South-Central Asia [2].

A marked increase in melanoma incidence has been observed in many countries, even where the rates were formerly low. It may be related to a change in sun-behaviour, with the result that more people are exposed to UV radiation throughout their lives, moreover intensely in adolescence/early adult life [5]. In the Nordic countries, for example, the average increase is some $30 \%$ every 5 years $[3,16,17]$. It is assumed that this latitudinal gradient may be related to the tendency for northern Europeans to vacation in sunny climates, resulting in intense, intermittent sun exposure. It is estimated, that the average annual increase in melanoma incidence for the Caucasian population is approximately 3-7 \% per year worldwide [18].

A marked increase in melanoma incidence in some Central and Eastern Europe (e.g. the Slovak and Czech Republic [19], Hungary, Slovenia etc. [20]) is apparent during approximately the same period of time and may be indirectly influenced by recent changes in socio-economic status. For example, in the SR the "gentle revolution“ in 1989 not only removed 
a totalitarian regime and renewed human rights and liberties (including the freedom to travel beyond the borders of the state), but also resulted in fundamental changes in the economy. Taking into account available factors of the improvement of the standard of living and several other measurable determinants of the quality of life leads to the conclusion that real wages, and with them the purchasing power of the population in contrast to 1989 , actually declined slightly to 1993. Subsequently, however, up to 2007, a growth of $30 \%$ in real wages was recorded and a majority of other aspects of the standard of living improved for a large section of the population of the SR [6]. From 2003 to 2010, the trend of vacations, mainly at seaside/mountainous destinations [6], for several days has had a remarkably upward trend [6], although the national statistics about the number of vacation days from 1989-2003 are not available. Significant changes in the melanoma incidence evolution, revealed by the joinpoint analysis in the SR in both genders in the same time period, can be in a certain manner influenced by changes in holidaymaker habits (in terms of more frequent traveling into sunny and seaside destinations) after the fall of communism in the y. 1989. The joinpoint analysis showed a significant acceleration of increment of ASR-W incidence in both genders since the y. 1997, i.e. 8 years after the liberation of borders. We assume, that in certain percentage the latency period since the increase of quantity of vacationists at seaside locations until the registration of the increment of incidence, can represent the inevitable period for manifestation of malignant melanoma after increased sun exposure. Similar situation with incidence time-trends has been registered e.g. in the Czech Republic, where in early nineties, after the borders were opened, increased travel to areas with high sun risks [19]. The increase of melanoma incidence after the y. 1997 in the SR was more accelerated in men than in women and concurrently we register moderate increase in the number of cases in the younger age groups [4] in both genders between $y$. 2000-2005. That might be the result of the increased exposure of children to solar radiation after 1989, although some of the increase may also be accounted to increased surveillance and early detection, as well as changes in diagnostic criteria [6]. The difference in acceleration of the incidence increment in men and women can be influenced by various factors, e.g. behaviour by sunbathing, hobbies, sunscreen usage with sun protection factors (SPF), clothing as a form of skin protection etc., which was revealed by Vranova et al. [19]. In this study higher incidence rates of cutaneous melanoma were observed in females in younger age categories, compared to males. The explanation, which was similarly hypothesized by Vranova et al. (20), may be connected with the expanded use of indoor tanning - solaria visits, predominantly by young women. However, there is no epidemiology data in this area accessible in the SR. Studies show that 25 to $40 \%$ of young women used indoor tanning in the past year. Mothers often accompany their daughters during the first tanning experience, thus, giving permission for underage tanning and establish- ing a pattern of regular tanning that carries over into young adulthood [22]. In the SR, the situation is reversed after the age-groups of 50-59 y. - a substantial increase was registered predominantly in males. This fact may be explained by leisure (skiing or mountaineering) or lifelong skin exposure to an ozone depleted environment [20].

Active surveillance may cause a modest temporary increase in the value of incidence by catching the prevalent cases of the illness among the population, but much of the increase is considered to be real and linked to changes in behaviour affected by solar radiation [5]. Even though the analysis of the melanoma incidence time-trend development in the SR does not consider the relationship of changes in the number of dysplastic naevi, nor topography and Breslow thickness, changes in behaviour towards solar radiation is probably the most common factor, in view of the character of the climate and vacation periods in the SR. It may remain a major risk for the future development of melanoma and result in a higher incidence in those individuals with pale, non-acclimatized white skin [23]. Changes in the socio-economic situation among the countries in Central and Eastern Europe after the fall of the totalitarian regimen and the increase in the number of vacation-days in destinations with intensive solar radiation may be one of various factors, which has contributed in the marked increase in melanoma since the late 90 s of the last century.

The mortality rates worldwide have a lesser variation with geography than incidence. Compared with those in Western Europe, in Eastern Europe the mortality rates are higher [18]. According to the data of IARC WHO, the highest mortality in 2008 was estimated to be in Norway, followed by Iceland and Croatia in males and Slovenia and Northern Ireland in females. The SR belongs to the countries with relative high mortality rates. The lowest mortality rates for both genders were estimated to be in Egypt and some East-Asian countries [24]. Despite more vigilant screening and early detection efforts, the melanoma mortality rate in males has increased in many countries over the last 25 years while it remains relatively stable in females [24].

According to the joinpoint analysis in the SR in men there is a registered continual increase of standardized mortality, however it is remarkably slower than incidence increment. The situation of mortality among women is slightly better than among men, whereas the joinpoint analysis stated a significant increment of mortality between y. 1968-1999 (while the increment was a little slower than in men), but the mortality remained stabilized after y. 1999.

The relative survival of patients diagnosed with melanoma is relatively high and has been steadily increasing in many countries [25]. For the period 1999-2003 in Nordic countries it ranged between $78 \%$ (Norway) to $90 \%$ (Iceland) in males and $88 \%$ (Norway) to $91 \%$ (Iceland) in females [26]. In 1995-2000 the overall 5-year relative survival in the US STEER 9 registries population was $92.4 \%$ in white females, $89.1 \%$ in white males, $75.7 \%$ in black females and $72.2 \%$ in 
black males. Published data on 5-year relative survival in the SR also shows an improvement in both genders, but are more favourable to women. However, the last published survival rates of $53.2 \%$ in males and $79.3 \%$ in females are lower from a global perspective. It is difficult to explain the phenomenon; the preceding increase in the number of clinical stage I cases was probably only at the expense of a lower number of nonidentified stages, in so far as the values especially for clinical stages II and IV remained constant. In the SR, the adjuvant therapy (interferon) is applied only for clinical stages IIB and more advanced (due to the limitations of health insurances), in some western countries it is applied from clinical stage IB, which may also influence the survival rates. In the SR since 2000 there was an increase in public awareness campaigns (e.g. Euromelanoma Day), focusing on primary and secondary prevention, but the participation still remains low. To a certain degree the delayed accessibility of modern treatment (namely adjuvant), may play a role in the decline of the patient's survival. This tendency is more apparent in post-communist bloc countries and was recorded also in some other malignancies in the SR [27].

It is pointed out that in the SR one of the very important risk factors for the development of melanoma are the changes in sun-behaviour and an increase in the amount of exposure of the population to solar radiation. Probably, as in several other countries of the former eastern bloc, changes in incidence tendencies may also be affected by the changes in socio-economic status of the country. The liberation of the borders, the possibility to travel abroad, an increase in the standard of living and the number of vacation-days spent abroad are in agreement with significant changes in the incidence of the disease. Even though the mortality and survival values in the SR are worse than in some western countries (which is probably influenced by the delayed accessibility to modern adjuvant treatment in comparison with western countries), the quantity of cases in clinical stage I among both sexes have a favourable upward trend.

\section{References}

[1] BARBE C, HIBON E, VITRY F, LE CLAINCHE A, GRANGE F Clinical and pathological characteristics of melanoma: a population-based study in a French regional population. J Eur Acad Dermatol Venereol 2012; 26: 159-164. http://dx.doi. org/10.1111/j.1468-3083.2011.04021.x

[2] FERLAY J, SHIN HR, BRAY F, FORMAN D, MATHERS C et al. GLOBOCAN 2008, Cancer Incidence and Mortality Worldwide: IARC CancerBase No. 10 [Internet]. Lyon: IARC; 2010. Available from: http: //globocan.iarc.fr/

[3] BOYLE P, LEVIN B (eds.): World Cancer Report 2008, Lyon: IARC, 2008.

[4] ONDRUSOVA M, PLESKO I, SAFAEI-DIBA C, OBSITNIKOVA A, STEFANAKOVA D et al. Comprehensive analysis of incidence and mortality of malignant tumours in the Slovak Republic [online]. Bratislava: NCR SR, NHIC, 2007. http: //www.nor-sk.org/.
[5] PARKIN DM, MESHER D, SASIENI P Cancers attributable to solar (ultraviolet) radiation exposure in the UK in 2010. Br J Cancer 2011; 105: 566-569.

[6] KISS S, SISKOVIC M, KULKA M Comparing of the standard of living in the Slovak Republic in 1989-2005 (in Slovak), Bratislava; 2006. Available from www.finance.gov. sk/ifp

[7] ONDRUSOVA M, PLESKO I, SAFAEI-DIBA C, ONDRUS D, KOPECKA I Cancer incidence in the Slovak Republic 2003, 2nd ed., Bratislava: NCR SR, NHIC, 2007.

[8] SAFAEI-DIBA C, PLESKO I, FRINDTOVA V, KOPECKA I, KRAKOVSKA B Cancer incidence in the Slovak Republic 2004. Bratislava: NCR SR, NHIC, 2008.

[9] SAFAEI-DIBA C, PLESKO I, OBSITNIKOVA A, DIENEROVA M, KALMANCOKOVA A Cancer incidence in the Slovak Republic 2005. Bratislava: NCR SR, NHIC, 2009.

[10] SAFAEI-DIBA CH, PLESKO I, HLAVA P (eds.). Cancer incidence in the Slovak Republic 2006. Bratislava: NCR SR, NHIC, 2010.

[11] SAFAEI-DIBA CH, PLESKO I, HLAVA P (eds.). Cancer incidence in the Slovak Republic 2007. Bratislava: NCR SR, NHIC, 2012.

[12] BRAY F, GUILLOUX A, SANKILA R, PARKIN DM Practical implications of imposing a new world standard population. Cancer Causes Control 2002; 13: 175-182. http: //dx.doi. org/10.1023/A: 1014344519276

[13] NATIONAL CANCER INSTITUTE, Surveillance research: http: //surveillance.cancer.gov/joinpoint/

[14] KIM HJ, FAY MP, FEUER EJ, MIDTHUNE DN Permutation tests for joinpoint regression with applications to cancer rates. Stat Med 2000; 16: 335-351. http: //dx.doi. org/10.1002/(SICI)1097-0258(20000215)19: 3<335: : AIDSIM336>3.0.CO; $2-Z$

[15] ZIVKOVIC MV, DEDIOL I, LJUBICIC I, SITUM M Sun behaviour patterns and perception of illness among melanoma patients. J Eur Acad Dermatol Venereol 2012; 26: 724-729. http://dx.doi.org/10.1111/j.1468-3083.2011.04154.x

[16] FUGLEDE NB, BRINCK-CLAUSSE UO, DELTOUR I, BOESEN EH, DALTON SO et al. Incidence of cutaneous malignant melanoma in Denmark, 1978-2007. Br J Dermatol 2011; 162: 349-353.

[17] MACKIE RM, HAUSCHILD A, EGGERMONT AM Epidemiology of invasive cutaneous melanoma. Ann Oncol 2009; 20 suppl. 6: . vi1-vi7. http: //dx.doi.org/10.1093/annonc/ $\underline{\operatorname{mdp} 252}$

[18] ERDEI E, TORRES SM A new understanding in the epidemiology of melanoma. Expert Rev Anticancer Ther 2010; 10: 1811-1823. http: //dx.doi.org/10.1586/era.10.170

[19] VRANOVA J, ARENBERGEROVA M, ARENBERGER P, STANEK J. VRANA A et al. Incidence of cutaneous malignant melanoma in the Czech Republic: the risk of sun exposure for adolescents. Neoplasma 2012; 59: 316-325. http: //dx.doi. org/10.4149/neo 2012041

[20] VRANOVA J, ARENBERGEROVA M, ARENBERGER P, VRANA A, ZIVCAK J et al. Malignant melanoma in the Czech Republic: Incidence and mortality according to sex, age and disease stage. Biomed Pap Med Fac 
Univ Palacky Olomouc Czech Repub. 2012 Nov 2. doi: 10.5507/bp.2012.081. [Epub ahead of print] http: //dx.doi. org/10.5507/bp.2012.081

[21] FERLAY J, PARKIN DM, CURADO MP, BRAY F, EDWARDS $B$ et al. Cancer Incidence in Five Continents, Volumes I to IX: IARC CancerBase No. 9 [Internet]. Lyon: IARC; 2010. Available from: http: //ci5.iarc.fr

[22] ROBINSON JK, BAKER MK, HILHOUSE JJ. New approaches to melanoma prevention. Dermatol Clin. 2012l; 30: 405-412. http: //dx.doi.org/10.1016/j.det.2012.04.006

[23] RIKER AI, ZEA N, TRINH T. The epidemiology, prevention and detection of melanoma. Ochsner J 2010; 10: 1056-1065.

[24] WHO, mortality database, http: //www.who.int/whosis/mort/ download/en/index.html (accessed on 24/11/2011)
[25] POLLACK LA, LI J, BERKOWITZ Z, WEIR HK, WU XC et al. Melanoma survival in the United States, 1992 to 2005. J Am Acad Dermatol 2011; 65(5 Suppl 1): S78-86.

[26] TRYGGVADÓTTIR L, GISLUM M, HAKULINEN T, KLINT A, ENGHOLM G et al. Trends in the survival of patients diagnosed with malignant melanoma of the skin in the Nordic countries 1964-2003 followed up to the end of 2006. Acta Oncol 2010; 49: 665-672. http: //dx.doi.org/10.3109/ $\underline{02841861003702528}$

[27] ONDRUS D, ONDRUSOVA M Recent patterns in testicular cancer incidence, mortality and survival in the Slovak Republic with reference to international comparisons. Cancer Invest 2012; 30: 545-551. http: //dx.doi.org/10.3109/ $\underline{07357907.2012 .700984}$ 